\title{
Anorectal Physiology: Test and Clinical Application
}

\author{
Hyeon-Min Cho \\ Department of Surgery, St. Vincent's Hospital, The Catholic University of Korea School of Medicine, Suwon, Korea
}

The physiology of the anorectal region is very complex, and it is only recently that detailed investigations have given us a better understanding of its function. The methods that are used for the evaluation of anorectal physiology include anorectal manometry, defecography, continence tests, electromyography of the anal sphincter and the pelvic floor, and nerve stimulation tests. These techniques furnish a clearer picture of the mechanisms of anorectal disease and demonstrate pathophysiologic abnormalities in patients with disorders of the anorectal region. Therefore, therapeutic recommendations for anorectal disease can be made best when the anatomy and the physiology of the anorectal region are understood.

Keywords: Anorectal physiology; Anorectal physiologic test; Biofeedback therapy

\section{INTRODUCTION}

Anorectal physiology is very complex. Comprehensive studies on this area have been performed only recently so that it can be understood better. The test methods are anorectal manometry, defecography, anal continence tests, electromyography for the anal sphincter muscles and the pelvic floor muscles, and nerve stimulation tests. Recently, together with such test methods, images of the pathophysiology of patients with not only normal anal continence and defecation but also disorders of continence and defecation could be obtained, so the importance of anorectal physiologic testing is increasing more and more $[1,2]$. Therefore, in this report, together with factors having effects on anal continence, physiological test methods performed commonly in a department of colorectal surgery and their clinical applications, as well as biofeedback therapies performed frequently in outpatient clinics, were examined.

Received: June 23, 2010 Accepted: July 25, 2010

Correspondence to: Hyeon-Min Cho, M.D.

Department of Surgery, St. Vincent's Hospital, The Catholic University of

Korea, Ji-dong, Paldal-gu, Suwon 442-723, Korea

Tel: +82-31-249-7084, Fax: +82-31-247-5347

E-mail : hmcho@catholic.ac.kr

(C) 2010 The Korean Society of Coloproctology

This is an open-access article distributed under the terms of the Creative Commons Attribution NonCommercial License (http://creativecommons.org/licenses/by-nc/3.0) which permits unrestricted noncommercial use, distribution, and reproduction in any medium, provided the original work is properly cited.

\section{FACTORS EXERTING EFFECTS ON ANAL CONTINENCE}

It is difficult to define anal continence clearly; nonetheless, it implies the ability to completely control defecation. Anal continence is a complex serial process achieved by conscious will and local reflex. For normal anal continence, the following complex factors are mutually and closely associated (Table 1).

\section{Stool volume and consistency}

Stool volume and consistency are considered to be the most important physical factors for anal continence [2]. Depending on the patient, anal incontinence with hard consistency stool is not seen, but anal incontinence with loose stool and gas is seen, or anal incontinence with a hard stool or loose stool is not seen, but anal incontinence with gas is seen. Such factors are important for the treatment of anal incontinence patients, and anal incontinence could be improved by changing a loose stool to a hard stool.

\section{Reservoir function}

The distal part of the colon functions as a type of reservoir and has a great effect on anal continence. The lateral angulation of the sigmoid colon and the valve of Houston play the role of a physical wall and suppress the further advancement of stools [2]. In addition, the compliance of the rectum is important for the reservoir function. 


\section{Sphincteric factors}

The tension of the anal sphincter muscles is the most important factor in maintaining anal continence. Maximal anal resting pressure is approximately $40-80 \mathrm{mmHg}$ [3]. The internal sphincter accounts for approximately $52-85 \%$ of the resting pressure (Table 2) [4-7]. The external sphincter has continuous tonic activity and thus acts not only in the resting period but also during sleeping [8]. Other sphincter muscles are relaxed during the resting period; hence, the external sphincter muscles could be considered to be special muscles. In voluntary contractions, the contraction duration is approximately $40-60$ seconds [9].

\section{Sensory components}

Rectal sensory perception

Mechanoreceptors expressed on the rectum induce extrinsic reflexes and intrinsic reflexes, which play very important roles in defecation. In the past, the mechanoreceptor was thought to be expressed on the pelvic floor [2]. Now, numerous mechanoreceptors have been shown to be also expressed on the rectal wall [10].

\section{Table 1. Factors related to anal continence}

\begin{tabular}{l}
\hline Stool volume and consistency \\
Reservoir function \\
Sphincter factors \\
Internal sphincter \\
External sphincter \\
Sensory components \\
Rectal sensory perception \\
Anal sensory perception \\
Neuropathways \\
Reflexes \\
Mechanical factors \\
Angulation between rectum and anal canal \\
Flutter valve \\
Flap valve \\
Corpus carvenosum of anus (anal cushion)
\end{tabular}

Table 2. Contribution of internal anal sphincter (IAS) to high-pressure zone

\begin{tabular}{llc}
\hline References & Recording device & $\begin{array}{c}\text { Contribution } \\
\text { of IAS (\%) }\end{array}$ \\
\hline Duthie and Watts [4] (1965) & Ballon catheter & 60 \\
& Perfused catheter & 68 \\
Frenkner and Euler [5] (1975) & Balloon catheter & 85 \\
Lestar et al. [6] (1989) & Balloon catheter & 55 \\
Cali et al. [7] (1992) & Perfused catheter & \\
& Males & 52 \\
& Females, parous & 59 \\
& Remales, nulliparous & 65 \\
\hline
\end{tabular}

\section{Anal sensory perception}

The anal canal expresses several types of sensory receptors and, thus, rectal contents can be perceived more precisely. They are receptors for pain, contact, pressure, friction, etc., they are expressed primarily in the distal half of the anal canal, and they may be present in the area approximately $5-15 \mathrm{~mm}$ above the dentate line.

\section{Neuropathways}

The sympathetic pathway to the internal sphincter emerges from the fifth lumbar spinal segment. The sympathetic nerves have a direct effect on the internal sphincter muscle cells, which prossess $\alpha$ - and $\beta$-adrenergic receptors. The internal sphincter also is supplied by preganglionic parasympathetic fibers that emerge from the second, third, and fourth sacral spinal segments. The cholinergic axons of these preganglionic parasympathetic neurons form synapses on the cell bodies of postganglionic parasympathetic neurons located within the anorectal wall proximal to the aganglionic sphincteric area. The axons of these neurons run downward to reach the internal sphincter. In the internal sphincter muscles, terminals of nerves running from mechanoreceptors expressed on the rectal wall purinergic receptors are present. Among them, the $\alpha$-adrenergic receptor represents contraction, and the others induce relaxation (Fig. 1).

\section{Reflexes}

When the anal area is pricked with a sharp object, the external sphincter muscle contracts which is referred to as the anal reflex. This anal reflex uses the S1-S4 nerves and occurs through the pudendal nerve. Another reflex is the reflex response of the anal sphincter muscles, which refers to the reflex response relaxing the internal sphincter muscles while contracting the

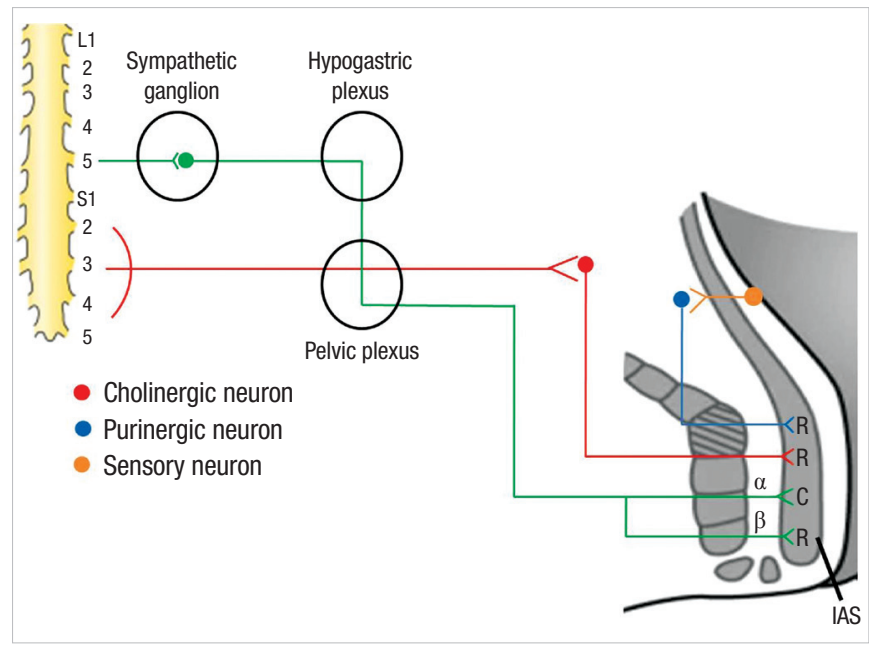

Fig. 1. Internal sphincter innervations showing muscle in state of relaxation (R) or contraction (C); internal anal sphincter (IAS)[2]. 
external sphincter muscles in response to the dilation of the rectum. The reflex response of the anal sphincter is very important for maintaining anal continence.

\section{Mechanical factors}

Angulation between the rectum and the anal canal

Angulation between the rectum and the anal canal is formed by the continuous contractile action of the puborectalis muscles, and it is the most important factor for maintaining overall anal continence. Measured by defecography, the angle formed by the anal canal and the rectum during the resting period is approximately 90 degrees, and the angle becomes larger during defecation.

\section{Effects of the flutter valve}

In theory, abdominal pressure compresses the rectum from the right and the left sides of the upper anal canal; thus, the rectum forms a slit shape, which facilitates anal continence itself. According to the theory, the highest pressure point should be located in the area above the anal sphincter muscles. However, the flutter valve mechanism is controversial because the highest pressure point is located in the middle area rather the upper area [11].

\section{Flap valve effect}

According to Parks et al. [12] when abdominal pressure is elevated, the anterior wall of the rectum is compressed and, thus, flap valve blocks the fecal stream above the upper end of the anal canal. Nonetheless, this effect is also controversial. When the Valsalva maneuver is actually performed, the anal pressure is always higher than the rectal pressure; thus, anal continence is thought to be due to the reflex contraction of the external sphincter muscles rather than the flap valve effect.

\section{Corpus cavernosum of the anus, anal cushion}

The corpus cavernosum of the anus, anal cushion, consists of blood vessels, smooth muscles and elastic connective tissues, and it allows high-quality anal continence.

\section{CHANGES AFTER COLOANAL ANASTOMOSIS}

Coloanal anastomosis performed to preserve the anal sphincter muscles after a protectomy mediates diverse effects on anal continence. This is thought to be associated with the reduction of the dilation of the intestine, ischemic changes at diverse levels, a decrease in anal pressure, etc. Anal incontinence is developed temporary in some patients. In the initial period after surgery, the anorectal inhibitory reflex is absent and appears again later, which is thought to be a phenomenon that appears as the neorectal compliance is improved with time.

\section{ANORECTAL MANOMETRY}

Anorectal manometry is a test measuring the function of the anal sphincter muscles objectively. This test can help to determine the most appropriate treatment method for anal incontinence patients by evaluating the contribution levels of the nerves and the muscles involved in anal continence, detecting the site of the anal sphincter injury caused by trauma, and evaluating the level. In addition, the levels of the functions of the sphincter muscles can be evaluated objectively prior to surgery that might affect anal continence, and is the test can be performed to evaluate the causes of chronic constipation in children and young adults. Generally, it measures the luminal pressure at 6-8 cm above the anal verge with $1 \mathrm{~cm}$ inter valusing a radial catheter. It shows the high pressure zone (which refers to the lengths of the anal sphincter muscles), the resting pressure, the squeezing pressure, the anorectal inhibitory reflex, the rectal sensibility, etc.

\section{High-pressure zones of the anal canal}

The maximal resting pressure is shown in the zone $2-3 \mathrm{~cm}$ above the anal canal. The measurement by using the continuous pull-through technique is more precise than the measurement by using the step-by-step pull-through technique [13] The measured high-pressure zone is about $2.5-5.0 \mathrm{~cm}$, and it is shorter in e females than in males [13-16]. When the anal sphincter muscles are contracted, the anal canal becomes longer, and it becomes shorter during defecation.

\section{Anal pressure \\ Resting pressure}

The internal sphincter muscles account for $52-85 \%$ of the pressure in the resting period. Generally, it is approximately 65-85 $\mathrm{mmHg}$, and the maximal resting pressure is shown in the area approximately $1-1.5 \mathrm{~cm}$ above the anal verge [15].

\section{Squeezing pressure}

Squeezing pressure is generated by the contraction of the external sphincter muscles and the puborectalis muscle. It is two times higher than the resting period.

\section{Anorectal inhibitory reflex}

When the rectum is dilated suddenly, the rectal wall is contracted slightly, and in the distal area of the anal canal, initially, the external sphincter muscles are contracted temporarily, and the resting period pressure is elevated (anorectal contraction reflex). Immediately after such a phenomenon, in the proximal area of the anal canal, together with a decrease in the resting pressure, the internal anal sphincter muscles are relaxed temporarily, which is referred to as the anorectal inhibitory reflex. However, in patients with colonic aganglionosis or coloanal anastomosis, the anorectal inhibitory reflex does not occur. 


\section{Rectal sensibility}

The rectal sensory threshold is the volume at the time of feeling something is in the rectum. The rectal capacity is the volume at the time the defecation urge is felt, and the maximal tolerable volume is the volume at the time when the urge to defecate is unbearable.

\section{ELECTROMYOGRAM}

An electromyogram is performed primarily to examine the presence or absence of relaxation failure of the puborectalis muscles. Generally, a surface electrode (plug electrode) is inserted into the anus, and the electric activities of the external sphincter muscles and the puborectalis muscles during the resting period, the squeezing period, and the pushing period are recorded. To assess the presence or absence of relaxation failure of the puborectalis muscles, whether or not the electric activities of these muscles are reduced during defecation (pushing period) is examined.

\section{PUDENDAL NERVE TERMINAL MOTOR LATENCY TEST (PNTML TEST)}

Among motor nerve conduction tests used for anorectal physiologic tests, the most frequently applied test is the PNTML test, and the test evaluates the nerve control of the external sphincter muscles. The method is to insert the rubber-glovecovered index finger to which an electrode is attached into the rectum, stimulate the pudendal nerve from the right and the left ischial spine areas, and measure the latency to the contraction of the external anal sphincter muscles. The normal value is $1.9 \pm 0.2 \mathrm{~ms}$, and a value elevated more than this implies injury of the pubic nerves [17]. A prolongation of this value can be observed in anal incontinence, solitary rectal ulcer syndrome, injury of the external anal sphincter muscles, and refractory constipation patients [2].

\section{DEFECOGRAPHY}

Defecography is a useful test method to find functional, as well as morphological, abnormalities in patients with defecation disorder. It is also a very useful test method to determine appropriate surgical treatment methods [18]. This test is of help to diagnose rectal intessusception, enteroceles, sigmoidoceles, paradoxic puborectalis contraction, descending perineum syndrome, and rectoceles. [19].

\section{ENDOANAL ULTRASONOGRAPHY}

Endoanal ultrasonography is of help to diagnose structural abnormalities of the anal sphincter muscles and adjacent tissues. Indications are preoperative staging of anal cancer, anal incontinence, perianal abscess, and complex and recurrent anal fistulae.

\section{CLINICAL APPLICATIONS OF ANAL PHYSIOLOGICAL TESTS}

\section{Anal incontinence}

Anal incontinence is diagnosed accurately by performing anorectal manometry, an electromyogram, a pudendal nerve terminal motor latency test, and anal ultrasonography; then, appropriate treatment methods are determined. For example, for patients with anal incontinence caused only by dysfunction of the anal sphincter muscles, even sphincter-saving surgery would not be of help, and in such patients, biofeedback treatments are sometimes effective.

\section{Constipation}

The measurement of colonic transit time, as well as anorectal manometry, is of help to diagnose severe chronic constipation, a megarectum, and a megacolon. Biofeedback therapies are effective in some patients.

\section{Rectocele}

Defecography is important not only for diagnosis but also for differential diagnosis between an enterocele and a sigmoidocele.

\section{Solitary rectal ulcer syndrome}

In an electromyogram, relaxation of the puborectal muscles may not be observed.

\section{Descending perineum syndrome}

In defecography, generally, the finding of a descending anal canal $3.5 \mathrm{~cm}$ more than during the resting period is shown. In cases associated with anal incontinence, the anal pressure is measured to be abnormally low by anorectal manometry.

\section{Anal fissure}

In most cases, the anal pressure is elevated during the resting period in anorectal manometry.

\section{Injury}

When planning a sphincter-saving procedure, it would be of help to assess the presence of an appropriate volume of muscles for successful sphincter-saving surgery by using anal ultrasonography.

\section{Inflammatory bowel diseases}

The dilation of the rectum is reduced in patients with inflammatory bowel diseases due to an increase in the sensitivity of the rectum or a reduction in the compliance. In Crohn's disease patients, it would be of help to predict the function of the 
rectum remaining after an ileorectal anastomosis [2].

\section{BIOFEEDBACK THERAPY}

Biofeedback therapy was first performed on anal incontinence patients in 1974 by Engel et al. [20] and now it is being performed at many institutions. The purpose of this therapy is to enhance the contraction capacity of the external sphincter muscles and to teach patients to perceive and react even if the rectum is dilated slightly. According to the Cochrane review reported in 2000, proofs of biofeedback therapy being effective for the reduction of anal incontinence were concluded not to be sufficient [21]. Nonetheless this therapy has advantages in that it is non-invasive and safe. Therefore, it is recommended as the first therapeutic method to be performed for anal incontinence patients, and it is thought to be effective as an adjuvant therapy after anal sphincter repair.

\section{CONCLUSION}

By the introduction of anorectal physiological tests, objective information on anorectal, as well as pelvic floor, functions that were difficult to understand in the past can be obtained. Thus, not only the diagnosis of functional, as well as morphological, diseases in this area but also a determination of treatment strategies and their results can be predicted. Nonetheless, such tests vary depending on the test laboratory and examiner, and the accuracy is limited; hence, treatments should be decided by considering clinical symptoms, not by completely depending on the tests.

\section{CONFLICT OF INTEREST}

No potential conflict of interest relevant to this article was reported.

\section{REFERENCES}

1. Park JG, editor. Coloproctology. 3rd ed. Seoul: Iljogak; 2005.

2. Gordon, PH, Nivatvongs, S. Principles and practice of surgery for the colon, rectum, and anus. 3rd ed. New York: Informa Healthcare; 2007.

3. Felt-Bersma RJ, Gort G, Meuwissen SG. Normal values in anal manometry and rectal sensation: a problem of range. Hepatogastroenterology 1991;38:444-9.

4. Duthie HL, Watts JM. Contribution of the external anal sphinc- ter to the pressure zone in the anal canal. Gut 1965;6:64-8.

5. Frenckner B, Euler CV. Influence of pudendal block on the function of the anal sphincters. Gut 1975;16:482-9.

6. Lestar B, Penninckx F, Kerremans R. The composition of anal basal pressure: an in vivo and in vitro study in man. Int J Colorectal Dis 1989;4:118-22.

7. Cali RL, Blatchford GJ, Perry RE, Pitsch RM, Thorson AG, Christensen MA. Normal variation in anorectal manometry. Dis Colon Rectum 1992;35:1161-4.

8. Kumar D, Waldron D, Williams NS, Browning C, Hutton MR, Wingate DL. Prolonged anorectal manometry and external anal sphincter electromyography in ambulant human subjects. Dig Dis Sci 1990;35:641-8.

9. Parks AG, Porter NH, Melzak J. Experimental study of the reflex mechanism controlling the muscle of the pelvic floor. Dis Colon Rectum 1962;5:407-14.

10. Ruhl A, Thewissen M, Ross HG, Cleveland S, Frieling T, Enck P. Discharge patterns of intramural mechanoreceptive afferents during selective distension of the cat's rectum. Neurogastroenterol Motil 1998;10:219-25.

11. Duthie HL. Anal continence. Gut 1971;12:844-52.

12. Parks AG, Porter NH, Hardcastle J. The syndrome of the descending perineum. Proc R Soc Med 1966;59:477-82.

13. McHugh SM, Diamant NE. Anal canal pressure profile: a reappraisal as determined by rapid pullthrough technique. Gut 1987; 28:1234-41.

14. Nivatvongs S, Stern HS, Fryd DS. The length of the anal canal. Dis Colon Rectum 1981;24:600-1.

15. Coller JA. Clinical application of anorectal manometry. Gastroenterol Clin North Am 1987;16:17-33.

16. Jameson JS, Chia YW, Kamm MA, Speakman CT, Chye YH, Henry MM. Effect of age, sex and parity on anorectal function. Br J Surg 1994;81:1689-92.

17. Roe AM, Bartolo DC, Mortensen NJ. New method for assessment of anal sensation in various anorectal disorders. Br J Surg 1986; 73:310-2.

18. Yang XM, Partanen K, Farin P, Soimakallio S. Defecography. Acta Radiol 1995;36:460-8.

19. Jorge JM, Habr-Gama A, Wexner SD. Clinical applications and techniques of cinedefecography. Am J Surg 2001;182:93-101.

20. Engel BT, Nikoomanesh P, Schuster MM. Operant conditioning of rectosphincteric responses in the treatment of fecal incontinence. N Engl J Med 1974;290:646-9.

21. Norton C, Hosker G, Brazzelli M. Biofeedback and/or sphincter exercises for the treatment of faecal incontinence in adults. Cochrane Database Syst Rev 2000;(2):CD002111. 